\title{
What affordances do open-ended real-life tasks offer for sharing student agency in collaborative problem-solving?
}

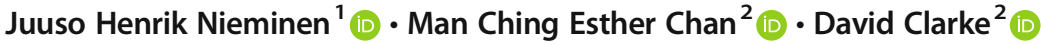

Accepted: 24 May 2021/ Published online: 18 June 2021

(C) The Author(s) 2021

\begin{abstract}
The important role of student agency in collaborative problem-solving has been acknowledged in previous mathematics education research. However, what remains unknown are the processes of agency in open-ended tasks that draw on real-life contexts and demand argumentation beyond "mathematical". In this study, we analyse a video recording of two student groups (each consisting of four students) taking part in collaborative problemsolving. We draw on the framework for collaborative construction of mathematical arguments and its interplay with student agency by Mueller et al. (2012). This original framework is supplemented by (i) testing and revising it in the context of open-ended real-life tasks, with (ii) student groups rather than pairs working on the tasks, and by (iii) offering a strengthened methodological pathway for analysing student agency in such a context. Based on our findings, we suggest that the framework suits this new context with some extensions. First, we note that differences in student agency were not only identified in terms of the discourse students drew on, but in how students were able to shift between various discourses, such as between "mathematical" and "non-mathematical" discourses. We identify a novel discourse reflecting student agency, invalidation discourse, which refers to denying other students' agency by framing their contribution as invalid. Finally, we discuss the need to reframe "mathematical" arguments - and indeed student agency while the task at hand is open-ended and concerns real-life contexts.
\end{abstract}

Keywords Student agency $\cdot$ Collaborative problem-solving $\cdot$ Open-ended tasks $\cdot$ Real-life contexts

Juuso Henrik Nieminen

juuso.nieminen@uef.fi

Man Ching Esther Chan

mc.chan@unimelb.edu.au

David Clarke

d.clarke@unimelb.edu.au

Extended author information available on the last page of the article 


\section{Introduction}

Over 20 years ago, Forman et al. (1998) were struggling with the same issue as we do nowadays: How can research guide teachers to facilitate mathematical learning through collaborative argumentation? Collaborative mathematical activities do not just see students as individuals working together, but as a collective (Leeet al., 2006). Contemporary curricula around the world highlight the importance of mathematical collaboration; team-working skills have been introduced as "key twenty-first century skills" (OECD, 2013). Research on mathematics education has also shifted towards understanding the social factors of mathematics learning (Lerman, 2000). As Forman et al. (1998, p. 547) put it: "Mathematics can no longer be seen as a purely individual epistemic activity but rather as an activity which is social in a principled way".

What remains undertheorised is the multifaceted nature of mathematical collaborative problem-solving (CPS) in the context of open-ended tasks. Such tasks often require students to collaborate without direct guidance by the teacher (Chan \& Clarke, 2017; Langer-Osunaet al., 2020; Langer-Osuna, 2018; Yeo, 2017). According to Sullivanet al. (2015), open-ended tasks require the teacher to relinquish some level of control over student activity so that students have a chance to build their own mathematical arguments rather than just finding those established by the teacher. Furthermore, open-ended tasks sometimes draw on real-life contexts $^{1}$ that require students to use their personal experiences in the collaborative process of producing mathematical arguments (Jurdak, 2006; Yeo, 2017). Earlier research has elaborated on the literate (scholarly mathematical discourse connected to school learning and mathematical concepts) and colloquial (everyday spontaneous discourse, such as counting money) mathematical discourses (Ben-Yehuda et al., 2005; Moschkovich, 2007). However, how collaboration manifests as learners would need to shift between literate and colloquial mathematical arguments - and perhaps even non-mathematical arguments - has been rarely elaborated.

As Chan and Clarke (2017) argue, open-ended CPS tasks offer affordances for student collaboration, but the realisation of such affordances is highly dependent on the students involved and their interaction. Thus, student agency has been strongly connected with the collaborative construction of mathematical arguments during CPS (Boaler \& Greeno, 2000; Wagner, 2004, 2007). Broadly, agency is demonstrated when students take initiatives and make contributions during mathematical collaboration (Gresalfi et al., 2009; Mueller et al., 2012). Student agency is widely advocated in current educational research (Matusov et al., 2016), yet the paradoxical nature of "promoting someone's agency" (Nieminen et al., 2021) in mathematical CPS remains understudied (Nieminen \& Tuohilampi, 2020). Enactments of agency are complex; students might exert agency by resisting teachers' intentions by, for example, choosing to disengage from the task at hand (Alrø \& Skovsmose, 2003; Emirbayer \& Mische, 1998). Furthermore, how agency is shared between learners from different backgrounds during open-ended CPS remains undertheorised, even though it has been widely argued that such practices would benefit students with various backgrounds and abilities

\footnotetext{
${ }^{1}$ In our study, we refer to "real-life contexts" in a rather straightforward way: We simply refer to tasks which can only be solved with knowledge outside of the mathematics curriculum. For the purposes of our research questions, we deem this conceptualisation as sufficient. See for instance Beswick (2011) for a nuanced critique on the use of the term.
} 


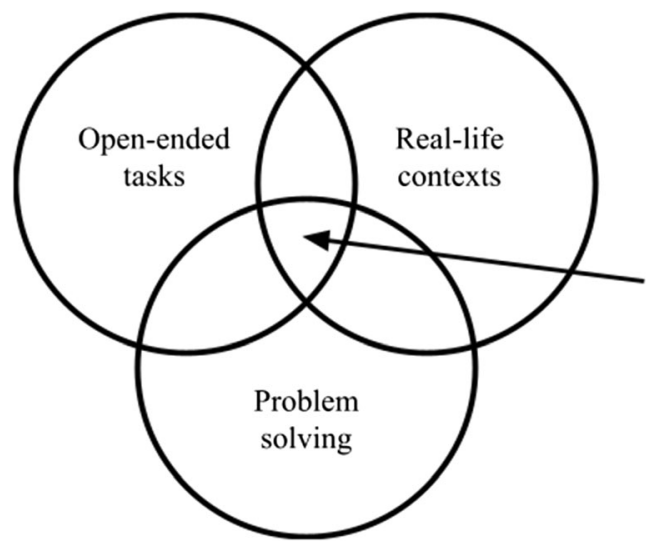

Where we

operate:

What

opportunities does

the intersection

offer for sharing

agency?

Fig. 1 Highlighting the contribution of the study

(Chizhik, 2001; Civil \& Hunter, 2015; CREA [Centre of Research in Theories and Practices that Overcome Inequalities], 2012; Davis \& Simmt, 2003).

In this study, we draw on the framework by Mueller et al. (2012) on collaborative construction of arguments and its interplay with agency to analyse two groups of students taking part in CPS. We apply the framework to open-ended tasks that utilise real-life contexts, or namely, other contexts than mathematics (Beswick, 2011; Jurdak, 2006; Yeo, 2017). As such, our study supplements earlier research on, for example, shared authority (Langer-Osuna et al., 2020; Langer-Osuna, 2018) in this novel context of open-ended real-life tasks. Furthermore, we empirically test the framework with small groups of four students rather than pairs as in the original article. We shed light on the complexity of the "social" in mathematical collaboration (Forman et al., 1998; Lerman, 2000) by focusing on how agency is shared, not shared, and restricted during CPS. In Fig. 1, we emphasise our contribution: What kind of affordances do mathematical problem-solving tasks that draw on both open-endedness and real-life contexts offer for shared agency?

\section{Student agency in mathematics collaborative problem-solving}

In this section, we introduce relevant literature related to our study. As our research focus is on student agency, we first introduce previous research on collaboration more generally as it is central to the idea of shared agency. We then present our conceptualisation of "student agency" and introduce earlier studies from the intersection of the three fields of research we operate in Fig. 1, again keeping our focus on student agency.

How to promote collaborative learning of mathematics has been a vibrant research area over the past decades. However, earlier literature on fostering meaningful and productive mathematical collaboration has largely been teacher-focussed, concerning how teachers could support desirable forms of collaboration and agency (Slavit \& Nelson, 2010; Stein et al., 2008). Yet as collaboration itself turns into a learning goal, it is necessary to examine how students collaborate without direct guidance by their teachers (Chan et al., 2018; Mueller et al., 2012). 
In this study, we draw on the concept of student agency to examine collaboration during CPS. As "agency" is not a universal concept but should be defined situationally (Matusov et al., 2016), we conceptualise the term in relation to mathematical CPS. In recent years, there have been multiple calls for applying sociocultural frameworks to examine student agency to challenge the dominant individualistic approaches (Arnold \& Clarke, 2014; Nieminen et al., 2021; Nieminen \& Tuohilampi, 2020). Following these suggestions, agency in this study is understood as a situationally constructed phenomenon, not as a student attribute but as a social phenomenon constructed through language and practices; this is a widely shared understanding in the field of mathematics education (Boaler \& Greeno, 2000; Gresalfi et al., 2009; Mueller et al., 2012; Wagner, 2004, 2007). Wagner (2004) implied that language acts as an instrument that offers a way to study the concept of agency indirectly. Analysing agency thus repels notions such as "have" or "lack" agency, since agency is not seen as residing in students but is constructed through their collaboration (Gresalfi et al., 2009). The situated nature of agency (in contrast to more stabilised concepts such as "identity") might reflect larger societal positions of agency and non-agency (Matusov et al., 2016). In this study, we focus on microlevel constructions of agency as students engage in collaborative problem-solving activities.

"Agency" is, however, a risky concept. Many related concepts (e.g. authority, positioning) hold a normative function (e.g. "we must support students' authority in mathematics"). While research on student agency often aims at "promoting" agency, students might use their agency for actions we consider as maladaptive (Emirbayer \& Mische, 1998). For example, Nieminen and Tuohilampi (2020) noted that mathematics students used their "promoted agency" not only to learn efficiently but to cheat, slack, and so forth. Students might agentically shift their focus from learning mathematics to something else (Alrø \& Skovsmose, 2003). Thus, sometimes it is desirable to hinder student agency. Furthermore, Nieminen and Tuohilampi (2020) emphasised that in addition to the goal of supporting student agency, teaching practices should prevent producing passive or lacking student agency. The processes of fostering agency and hindering the restriction of agency surely overlap, but they might also differ greatly.

We drew on a conceptualisation of agency based on language (Wagner, 2004) and utilised the framework by Mueller et al. (2012) that concerns agency in the construction of mathematical arguments (building on the work by Alrø \& Skovsmose, 2003). Mueller and colleagues investigated discourses during mathematical problem-solving to understand their connections with agency. The framework distinguishes between three different modes of mathematical collaboration: co-construction, integration, and modification. The distinction is based on the discourse students use during the collaboration mode, and further, these discourses define whether students act as primary or secondary agents.

Co-construction of arguments involves students engaging in a back and forth process during which "the argument is simultaneously built from the ground up" (Mueller et al., 2012, p. 378). This collaboration mode consists of negotiary discourse during which the students share their agency; in other words, the mathematical ideas go beyond those already internalised by any individual (see also Powell, 2006). During co-construction processes, it is not possible to determine primary or secondary agents, but all students share their agency. In contrast, during integration of arguments, a primary agent's argument is strengthened using arguments from their peers, who then act as secondary agents. Thus, it is possible to identify a primary agent who leads the collaboration process, yet the final argument is constituted by secondary agent(s) (Mueller et al., 2012). Integration processes involve both informative (seeking or providing information without judging; from the primary agent to the secondary agent) and interpretive (teasing out the meaning behind a peer's argument; from the secondary 
agent to the primary agent) discourses. Finally, modification of arguments occurs as primary agents "attempt to correct a peer or assist him/her in making sense of a model of argument that was originally expressed in an unclear or incorrect way" (Mueller et al., 2012, p. 378). Modification processes consist of interpretive discourses as described above.

As the teacher is usually not directly guiding CPS, the importance of careful task design for student agency is emphasised (Chan et al., 2018; Chan \& Clarke, 2017). Chizhik (2001) argued that productive collaboration depends on task design as open-ended tasks might provide more opportunities for non-dominant student groups to participate in argumentation. Civil and Hunter (2015) reminded that real-life contexts might better enable non-dominant mathematics students to "be themselves, that is, they could bring in their cultural ways of being and acting, including their home language(s), their ways of speaking, their use of humor, and values not necessarily encountered in other areas of their schooling" (p. 308). Heterogeneous student groups and novel task designs have been shown to enable reimagining agentic positions for students who are traditionally seen as underachievers (Esmonde \& LangerOsuna, 2013; DeJarnette \& González, 2015). Focusing on students' authority in mathematics, Langer-Osuna et al. (2020) found out that while students were able to share both social and intellectual authority in mathematics, it was social authority that was more malleable and dynamic.

One of Mueller et al. (2012) study's main implications is that even though coconstruction of mathematical arguments is often valued, the integration and modification processes also play important roles in mathematical collaboration. They argued that interpretive and informative discourses can be as "powerful" (Mueller et al., 2012, p. 384) as negotiary discourses since some students might not be willing to use all three discourse patterns. It was then stated that none of the processes should be valued over others. Whether all students would be able to participate through many forms of collaboration is exactly in the scope of this study.

Furthermore, applying the framework by Mueller et al. is important in real-life contexts that require argumentation beyond mathematics. Earlier research has focussed specifically on mathematical argumentation (Campbell et al., 2020; Nordin \& Björklund Boistrup, 2018); so does the framework by Mueller et al. We extend our analysis of agency to nonmathematical argumentation as well, showing that the intertwinement of "mathematical" and "non-mathematical" as agency is shared and non-shared in CPS.

\section{Study aim}

The overall study aim is to understand shared (and non-shared) agency in mathematical collaboration as the task design is both open and draws on real-life contexts (Fig. 1). We applied Mueller et al.'s (2012) framework to analyse student agency based on the video recordings of two groups of students taking part in CPS. The Mueller et al. framework was elaborated by offering an analytical pathway for identifying the discourses (negotiary, interpretive, informative). The following research questions (RQs) were formulated: (RQ1) What modes of collaboration (co-construction, integration, modification) did the students take part in while solving the open-ended CPS task? How did the modes of collaboration reflect student agency (shared, primary, secondary agency)? (RQ2) What kind of mathematics discourses did students draw on (literate, colloquial, non-mathematical, or other discourses)? RQ2 was open for new discourse types as well. 


\section{Methodology}

\subsection{Participants and data collection}

This study drew its data from the larger Social Unit of Learning Project (Chan et al., 2018). Intact Year 7 classes from a secondary school in metropolitan Melbourne were recruited with their usual teacher to exploit existing student-student and teacher-student interactive norms. Eleven classes of Year 7 students (12 to 13 years old; 264 students in total) participated in the project. Each class participated in a 50- to 60-min session in the laboratory classroom as the students completed problem-solving tasks individually, in pairs, and in small groups (4-6 students). The laboratory classroom facility was designed to allow simultaneous and continuous documentation of classroom interactions using multiple cameras and microphones. The current study focused on the small group work (20 min) of two groups.

The data collected for the project included the following: all written material produced by the students; video footage of all of the students during the session; transcripts of teacher and student speech based on the video recording; and recording and transcripts of pre- and postsession teacher interviews.

The teacher of each class was asked to assign the groups based on what the teacher thought would function well for the CPS tasks. The current study included two groups of four students from the same class. Group 1 included Aruna (female), Natalie (female), Michael (male), and Daniel (male), and the second group included Nafisa (female), Ji-na (female), Adrian (male), and Nicholas (male) (pseudonyms). In the post-session interview, the teacher explained that the groups were assigned so that the students within one group would be "dissimilar but not too dissimilar" in mathematical ability. These two groups were chosen for the present study based on two criteria. First, all of the students in the group had sufficient English fluency that would enable them to participate in the task. Also, for this analysis, we chose groups who were able to produce a finalised solution to the task. Based on the pre-session interview with the teacher, we characterised the eight students. The teacher framed Michael and Daniel as a "fairly high-ability pair", while contrasting Aruna and Natalie as a "fairly low-ability pair". Furthermore, the teacher characterised Aruna as "probably the weakest student in the class", and Natalie as "not as weak as Aruna is but probably in the lower end of the middle". Of the second group, the teacher claimed Nafisa and Ji-na being a "middling" ability pair, and Adrian and Nicholas were described as "the highest performing students".

The problem-solving task that the students undertook drew from previous research (e.g. Clarke \& Sullivan, 1990) and was purposefully chosen to make the thinking and social processes of the problem-solving activity visible. The task was open in terms of answer, methodology, and complexity (Yeo, 2017); it allowed students to use different strategies and forms of knowledge and experience:

Fred's apartment has five rooms. The total area is $60 \mathrm{~m}^{2}$. Draw a plan of Fred's apartment. Label each room, and show the dimensions (length and width) of all rooms.

\subsection{Analytical pathway}

The analysis was based on transcripts of the video-recorded CPS sessions. The analysis was first conducted for group 1 to trial and refine the analytical procedure. After refining and 
confirming the analytical path, the same set of analytical steps was conducted in the same manner for group 2. Throughout the analysis, the findings and the process were compared and discussed until a consensus between the research team members was reached (Clarke et al., 2006).

The purpose of this first analytical step was to familiarise the authors with the dataset and to divide the data into manageable "building blocks" for further analysis. First, the first author identified the negotiative events (Clarke, 2001) from the transcript. A negotiative event was defined as "an utterance sequence constituting a social interaction with a single identifiable purpose" (Chan \& Clarke, 2017, p. 959). The size of a unit was kept as small as possible so that each negotiative event between four (or fewer) students would only contain this one identifiable purpose, and each unit was coded through a data-driven in vivo coding process (Saldaña 2016). The video data were frequently referred to during the analysis to confirm the purpose of each sequence. This first phase concluded in 63 negotiative events with group 1 and in 48 events with group 2. The unclear units were constantly discussed between the authors during the coding process until consensus was met.

The negotiative events were used as "building blocks" to construct coherent patterns with an identifiable start, a student clearly initiating a new topic, and a final argument; these discursive patterns, consisting of multiple negotiative events, were called Discussion Topics. The negotiative events were read through and classified based on their in vivo code - each building block was connected and sequenced with those that belonged to the same Discussion Topic. For example, a Discussion Topic by group 1 was "What is the size of the bathroom?" The Discussion Topic consisted of four negotiative events (Events IDs 14, 21, 34, and 36), with the final argument being "two by two". In this example, the students were discussing this topic in a rather disorganised way-after the discussion about the size of the bathroom in Event ID 14, Event ID 15 concerned the size of a guest room, and Event ID 16 included the theme of "apartment kitchens normally being very small".

After reconstructing the student conversation, each utterance (or small clusters of them) within these collaboration modes was coded using Mueller et al.'s (2012) classification for negotiary, informative, and interpretive discourses. The utterances that could not be clearly categorised as one of the discourses (such as brief utterances like "okay") were either left uncoded or were coded as a part of some other utterance, depending on the context. The uncoded utterances were re-examined for discourses that were outside Mueller et al.'s categories.

Utilising the categories for negotiary, informative, and interpretive discourses, each Discussion Topic was coded as co-construction, integration, or modification. Following Mueller et al. (2012), the coding process for each collaboration modes was conducted:

- If the set of negotiative events included only negotiary discourse, the Discussion Topic was coded as co-construction.

- If the process included both informative and interpretive discourses, it was coded as integration.

- If the process included only interpretive discourses, it was coded as modification.

It is notable that many Discussion Topics included elements of other discourses too; the coding took a comprehensive approach that considered the process as a whole. For example, the Discussion Topic "What is the size of the bathroom?" (Event IDs 14, 21, 34, 36) was coded as a "modification process". However, in the middle of the collaboration mode, Event ID 34 
included utterances coded under "negotiary discourse". In these utterances, the students were "ping-ponging" between ideas about the size of the bathroom, with Natalie drawing while Daniel and Aruna suggested ideas. In the end, Daniel took over the situation through informative discourse ("so the toilet should be like one by one").

To answer RQ2, we needed an analytical tool to differentiate between mathematical and other forms of discourse. In real-life contexts, where does the boundary lie? We examined whether and how students would use mathematical discourse (Moschkovich, 2007). We drew on Ben-Yehuda et al.'s (2005) distinction between literate and colloquial mathematical discourses (see also Moschkovich, 2007). Literate discourses are based on the use of mathematical concepts, definitions, theorems, and mathematics learnt in school; colloquial discourses deal with everyday; and spontaneous mathematics. Our purpose was not to strictly categorise all mathematical language in these two silos, nor was our focus on where the boundary between "colloquial" and "non-mathematical" lies. Instead, we used this simplistic categorisation to better understand student agency in CPS, and we noticed that the categorisation was indeed fit for this purpose.

We coded each utterance in terms of whether it showed literate or colloquial mathematics discourse. Following the first analysis phase, some coded units consisted of two or more utterances. The following decisions were utilised:

- If the unit contained formal mathematical concepts or definitions (e.g. "four times two"), it was coded as literate discourse.

- If the unit contained language that concerned mathematical ideas without using formal concepts (e.g. "the kitchen needs to be bigger than the bathroom"), it was coded as colloquial discourse.

- If the unit could not be coded as either literate or colloquial discourse, it was simply coded as "unclear."

\section{Overview of the collaborative processes}

Before presenting the findings, we briefly describe the CPS process for both groups. Group 1 started by listing all the possible options for rooms. The students first discussed who lives in the house and then started to sketch their ideas about the size of each room (the living room, bathroom, spa, guest room, kitchen). Only after this did the students start to think about the position of each room, as well as the shape of the whole apartment. The turning point was when Daniel realised their plan for the apartment went over by $10 \mathrm{~m}^{2}$ from the task specification and started to fix this. After adjusting the size of the living room, bathroom, and kitchen, another turning point occurred: Michael noted that now their proposed solution was $20 \mathrm{~m}^{2}$ short of the task specification. For the remaining task time, the group focused on increasing the area of the apartment. Their solution (Fig. 2) did not form a coherent apartment, which reflects the way their CPS process concentrated on the individual rooms. Throughout the process, all four students took part in the discussion; Michael was the only one taking larger breaks from engaging with the task. However, whenever Michael participated, he took the lead in the mathematical discussion. Overall, Daniel and Natalie were the ones leading the conversation.

The CPS process of group 2 was strikingly different. Simply watching the video revealed that the group was not working effectively: Most of the time, Adrian and Nicholas were 


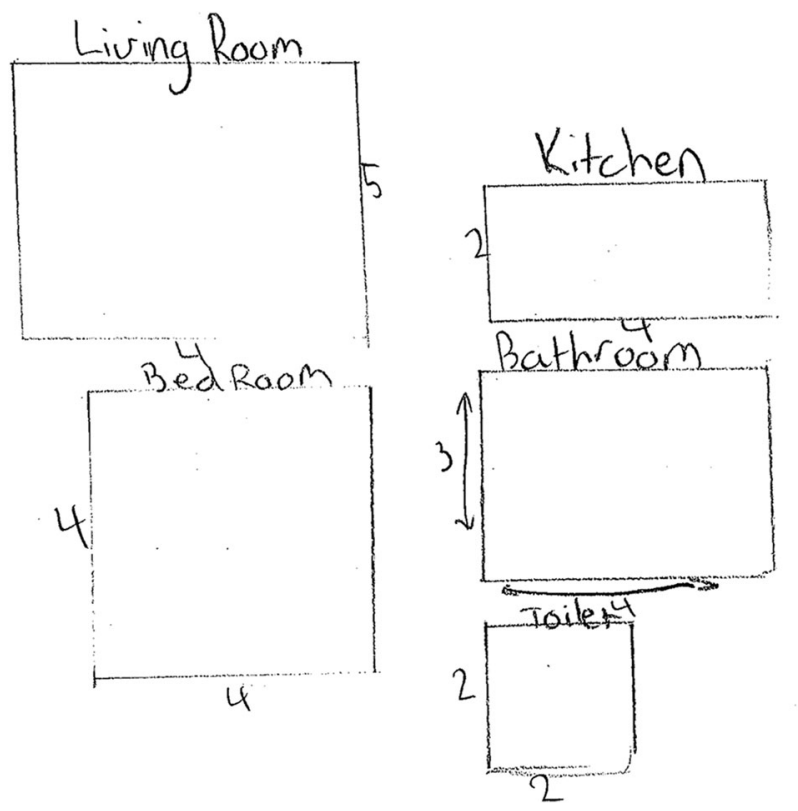

Fig. 2 The final solution of group 1

solving the problem together. The process started with all four students pondering about what the five rooms could be. The group did not have similar kinds of "turning points" as group 1 had, but they constantly reflected on and adjusted their plan. For example, at one point, Adrian, Nicholas, and Nafisa realised they needed to add one extra square meter, which is why they ended up including a cupboard in their final solution. Group 2 concentrated on coming up with a solution that represented a real-life apartment, and they thought about the locations of the doors so that Fred could move around in the apartment (Fig. 3). The students seemed to have

$$
1 \mathrm{~cm}=1 \mathrm{~m}
$$

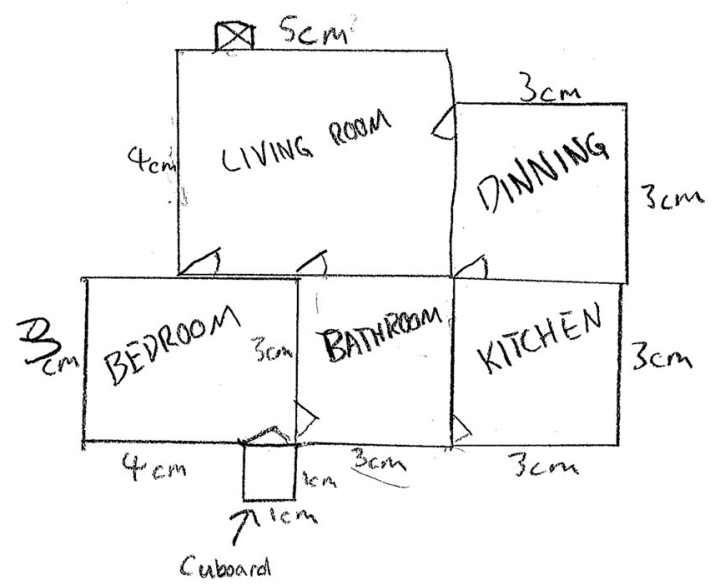

$\Delta=$ Door

$\otimes=$ Front Door

Fig. 3 The final solution of group 2 
different roles in the CPS process. Nicholas concentrated on solving the task, and he often seemed rude as he took the lead in the process and did not always appreciate everyone's contribution. Adrian tried to involve the girls ("you can choose where the rooms are in the house") but oftentimes failed. Ji-na was not keen on participating in solving the task-at some point she shrieked "I seriously don't want to do this", yet still continued collaborating with the others. Nafisa was eager to participate, but many times her contributions were ignored.

\section{Findings}

The findings are represented in three phases. First, we provide an overview of the data (RQ1): What collaboration modes were identified, and how was agency constructed within them? Second, we shed light on how the open-ended real-life task offered affordances for sharing (and not sharing) agency during the collaboration modes by offering multiple examples (RQ2). Finally, we introduce a new discourse type that was identified in our analysis.

\subsection{Overview of the modes of collaboration and agency}

The quantified collaboration modes of the two groups are presented in Tables 1 (group 1) and 2 (group 2). We provide descriptions of each Discussion Topic, the student who initiated it, the

Table 1 The Discussion Topics of group 1

\begin{tabular}{|c|c|c|c|c|}
\hline $\mathrm{DT}_{\mathrm{ID}}$ & Name of the collaboration process & Initiator & $\begin{array}{l}\text { Form of } \\
\text { collaboration }\end{array}$ & Final argument \\
\hline 1 & $\begin{array}{l}\text { What are the rooms of the } \\
\text { apartment? }\end{array}$ & Daniel & Co-construction & $\begin{array}{l}\text { Living room, kitchen, bathroom, guest } \\
\text { room, bedroom. }\end{array}$ \\
\hline 2 & What is the size of the apartment? & Daniel & Co-construction & Smaller than a house. \\
\hline 3 & Who lives in the apartment? & Natalie & Co-construction & It's a Fred named Boy. \\
\hline 4 & What is the size of the living room? & Daniel & Integration & Six times five. \\
\hline 5 & What is the size of the bathroom? & Natalie & Modification & Two by two. \\
\hline 6 & What is the size of the spa? & Daniel & Integration & Four times four. \\
\hline 7 & What is the size of the guest room? & Natalie & Co-construction & A bit smaller than the bedroom. \\
\hline 8 & What is the size of the kitchen? & Natalie & Co-construction & Two and four. \\
\hline 9 & What is the shape of the apartment? & Daniel & Co-construction & See Image 1. \\
\hline 10 & $\begin{array}{l}\text { How are the rooms positioned to } \\
\text { each others? }\end{array}$ & Natalie & Co-construction & See Image 1. \\
\hline 11 & How big is a square meter? & Daniel & Co-construction & That's a perfect square. \\
\hline 12 & We went over by 10 & Daniel & Integration & $\begin{array}{l}\text { We still have the guest room and the } \\
\text { bed room. }\end{array}$ \\
\hline 13 & New size of the living room & Natalie & Integration & Five by four. \\
\hline 14 & New size of the bathroom & Natalie & Co-construction & Three by four. \\
\hline 15 & New size of the bedroom & Michael & Modification & Four by four. \\
\hline 16 & We're down by 20 & Michael & Integration & Eight by four. \\
\hline 17 & We could have a sun room & Daniel & Modification & No. You can just go outside. \\
\hline 18 & How big is the storage room? & Daniel & Integration & Two by two. \\
\hline 19 & $\begin{array}{l}\text { Guys, just - just a suggestion. You } \\
\text { can change this. }\end{array}$ & Michael & Integration & Nine by four. \\
\hline 20 & Revising the sizes of the rooms & Daniel & Co-construction & See Image 1. \\
\hline 21 & $\begin{array}{l}\text { Does every apartment have a } \\
\text { balcony? }\end{array}$ & Natalie & Integration & Not every apartment has a balcony. \\
\hline
\end{tabular}




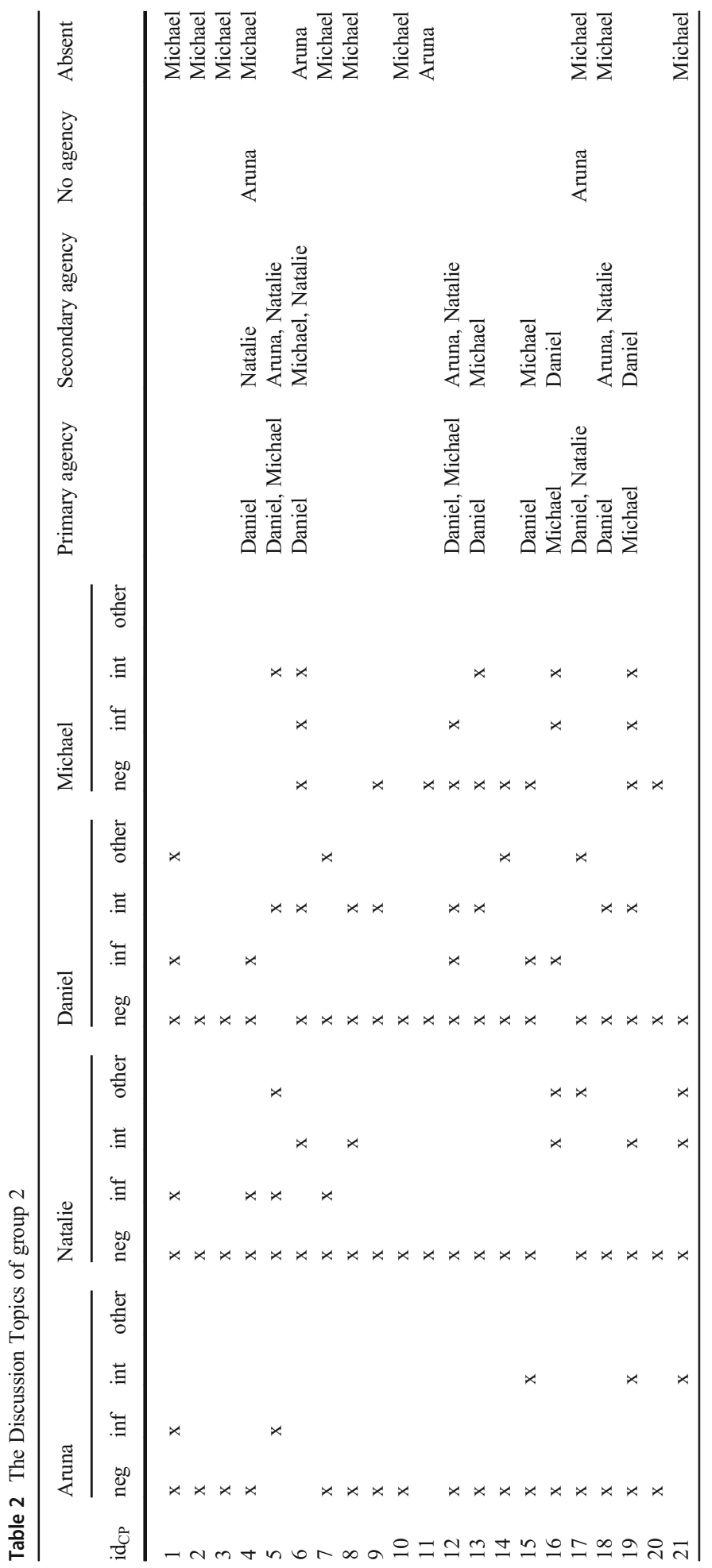


form of collaboration (co-construction, integration, modification), and the final argument (in vivo coded).

The CPS process consisted of many forms of collaboration for group 1, but the process of group 2 mainly involved co-construction. Daniel and Natalie initiated most of the Discussion Topics for group 1, whereas Adrian and Nicholas initiated all but one of them in group 2; Aruna and Ji-na never initiated a Discussion Topic. The final arguments vary from those that resemble literate mathematical discourse ("four by four") to those drawing on colloquial discourse ("we do not need a backyard since this is an apartment"), highlighting the nature of the open-ended real-life task.

Tables 3 and 4 present the discourses the student took part in during each Discussion Topic (neg = negotiary; inf $=$ informative; int $=$ interpretive). We distinguished between primary and secondary agents according to Mueller et al.'s (2012) classification. The blanks in Tables 3 and 4 related to these terms refer to shared agency during coconstruction processes during which primary or secondary agents could not be defined, which again draws on the definition by Mueller and colleagues. In group 1, agency was shared during most of the co-construction processes (Tables 2 and 3). However, in group 2 , some of the co-construction processes involved identifiable primary and secondary agents; this will be elaborated in relation to the invalidation discourse. Finally, we departed from Mueller et al. (2012) by distinguishing between lacking agency and being absent from collaboration. "Absent" means that the particular student took no part at all in the collaboration process, whereas "no agency" means that the student tried to participate but was ignored or that their contribution was debunked (which, again, will be elaborated on in relation to the invalidation discourse).

Table 3 Discourses in each Discussion Topic and forms of agency for group 1

\begin{tabular}{|c|c|c|c|c|}
\hline $\mathrm{DT}_{\mathrm{ID}}$ & Discussion Topic & Initiator & $\begin{array}{l}\text { Collaboration } \\
\text { process }\end{array}$ & Final argument \\
\hline 1 & What are the five rooms? & Adrian & Integration & $\begin{array}{l}\text { Bathroom, living room, dining room, } \\
\text { cupboard, bedroom. }\end{array}$ \\
\hline 2 & The size of the bathroom & Adrian & Co-construction & Nine square meters. \\
\hline 3 & The size of the living room & Adrian & Co-construction & Five times four. \\
\hline 4 & Revising the plan & Adrian & Co-construction & $\begin{array}{l}\text { Each room has to be } 10 \text { square meters } \\
\text { now. }\end{array}$ \\
\hline 5 & The size of the bedroom & Nafisa & Co-construction & 21 square meters. \\
\hline 6 & The size of the dining room & Nicholas & Co-construction & Three by three. \\
\hline 7 & Adjusting the apartment in general & Nicholas & Co-construction & Extra square meter needs to be added. \\
\hline 8 & $\begin{array}{l}\text { Sharing the rest of the area for } \\
\text { kitchen and bedroom }\end{array}$ & Nicholas & Integration & $\begin{array}{l}\text { Bedroom is nine and the rest goes for } \\
\text { kitchen. }\end{array}$ \\
\hline 9 & $\begin{array}{l}\text { How to walk through the rooms in } \\
\text { the apartment }\end{array}$ & Adrian & Co-construction & See Image 2. \\
\hline 10 & $\begin{array}{l}\text { What are the doors of the } \\
\text { apartment? }\end{array}$ & Nicholas & Co-construction & See Image 2. \\
\hline 11 & The size of the cupboard & Adrian & Co-construction & One by one. \\
\hline 12 & Do we need a backyard? & Adrian & Co-construction & No. It's an apartment. \\
\hline
\end{tabular}




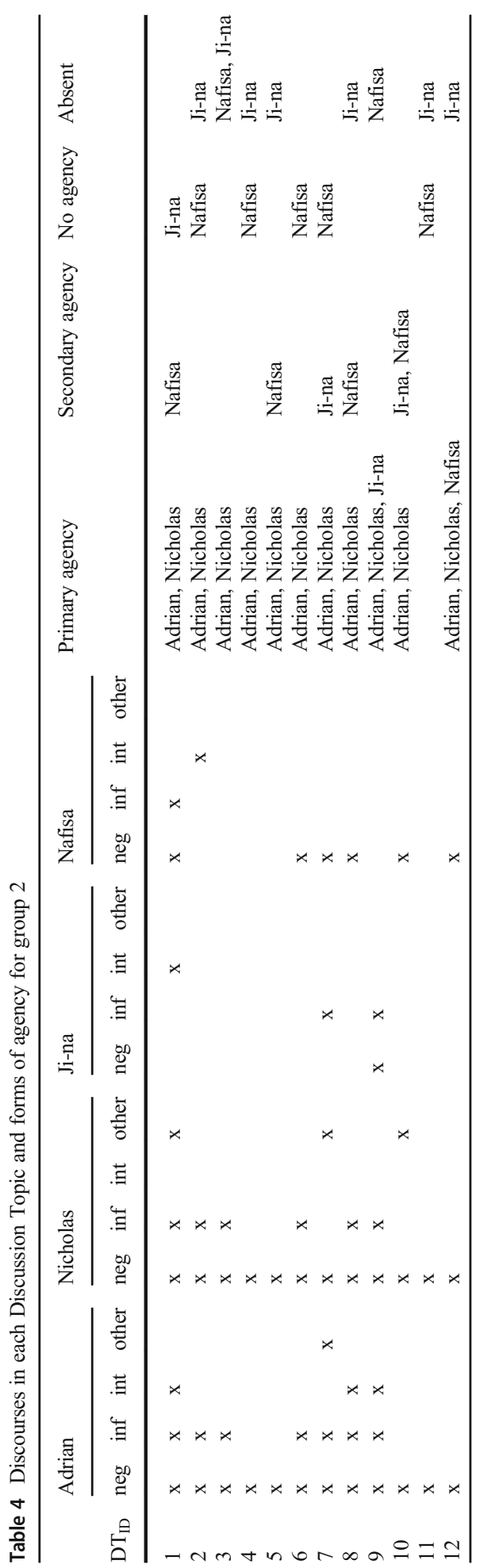




\subsection{Shifting between and beyond mathematical and non-mathematical}

In this section, we introduce the affordances of the open-ended real-life task offered for sharing agency. Examples are given in relation to all of the three collaboration modes (co-construction, integration, modification). The final arguments in the collaboration processes reflected both literate (e.g. "Three by four" by group $1, \mathrm{DT}_{\mathrm{ID}}=14$ ) and colloquial mathematics discourse (e.g. "That's a perfect square!" by group $1, \mathrm{DT}_{\mathrm{ID}}=11$ ). Furthermore, some of the final arguments seemed to reach beyond "mathematical" (e.g., "No. It's an apartment." by group 2, $\mathrm{DT}_{\mathrm{ID}}=12$ ).

Co-construction was the most common form of collaboration for both of the groups (Tables 1 and 2). At first glance, both tables tell a story of a rather successful story of mathematical problem solving. Tables 3 and 4 highlight that all of the students except for Ji-na had access to negotiary discourses that characterise co-construction. It seemed that the open-ended real-life task enabled the students to share their agency.

However, the co-construction processes did not only consist of literate mathematical discussion. Solving the CPS task required not only literate and colloquial mathematics discourses, but non-mathematical discourses as well. Both groups started solving the task by listing rooms that are traditionally found in Western apartments: kitchen, living room, bathroom, and bedroom. These processes - that included the students brainstorming by coming up with silly and funny proposals-were characterised by negotiary discourses. Some of the co-construction processes included no literate mathematics discourses at all, which made them inclusive for many students. In group 1, all the students shared their agency while discussing the five rooms $\left(\mathrm{DT}_{\mathrm{ID}}=1\right)$. Within such co-construction processes, there were often many utterances coded as "unclear" in terms of whether they were colloquial or not. For example, Excerpt 1 shows how group 1 discussed the differences between a house and an apartment. This brief co-construction process included the students discussing mathematical concepts such as ratios (as "tiny" is always tiny in relation to something) yet whether such ideas reflected "colloquial" or "non-mathematical" discourse is debatable.

\section{Excerpt 1: Group 1, $\mathrm{DT}_{\mathrm{id}}=2$}

Daniel: This is really big because apartments

Aruna: Are really tiny.

Daniel: You don't say.

Natalie: This is precisely my - my apartment's living room except it's like - like - like.

Daniel: I would say like six by five.

Excerpt 2 contains an example of a co-construction process in which literal and colloquial discourses were intertwined. In the example, Nicholas wonders about how big are bathrooms normally. This is yet another example of an utterance coded as "unclear", as understanding what "normal" means surely requires mathematical understanding, but other forms of knowledge too such as cultural knowledge about the sizes of bathrooms in modern societies.

Excerpt 2: Group 2, $\mathrm{DT}_{\mathrm{id}}=2$

Nicholas: So how big is a bathroom normally? 
Adrian: Uhmm. About...

Nicholas: Shower could be...

Nafisa: Ten square?

Nicholas: ...one metre.

Adrian: So it would about the - half of size of this.

Nafisa: Yeah. Like there. Yeah. About there.

Nicholas: No. A shower can be one square metre.

Adrian: Yeah. A one square metre.

Our analysis of literate and colloquial mathematics discourses revealed differences in students' collaboration patterns. Following the definition of co-construction (Mueller et al., 2012), none of the contributions by students could have been removed without disrupting the final argument. This did not mean that all of the contributions were equal in mathematical terms. A good example of this is Michael, who was absent from 10 of the 21 collaboration processes, but whose contributions were thoroughly characterised by literate mathematics discourses. Michael rarely engaged in conversations concerning general discussions about the positions of the rooms or how the rooms should be decorated. Many times, Michael "saved" the situation at hand. During a turning point for group 1, the students realised they had accidentally drawn an outline for a bedroom that is too small. Michael, who has been quiet for a while, suddenly initiated by offering help. What followed was a sequence during which his literate mathematics discourse was used to draw the conclusion on the size of the bedroom:

Excerpt 3: Group 1, $\mathrm{DT}_{\mathrm{id}}=12$

Michael: Guys, just - just a suggestion.

Natalie: I hate this table.

Michael: You can either...

Daniel: How're we going to - oh yeah, that's true. But that's outside. That's technically not...

Natalie: It could be like part of.

Michael: You can change this.

Aruna: I wish there was a.

Michael: You can change this to eight times four or - or you can change this.

Daniel: Why eight times four, that's huge?

Natalie: Yeah. It is huge.

Daniel: No, no, no. It's good.

In contrast, Nafisa and Aruna rarely took part in literate mathematics discourse, even when they did have access to negotiary discourses. Interestingly, we identified that other students "translated" these students' colloquial mathematics discourse into literate discourse. This can be seen in Excerpt 4. The examples show how Daniel and Michael translate Natalie's colloquial mathematics discourse into literate:

Excerpt 4: Group 1, $\mathrm{DT}_{\mathrm{id}}=13$

Aruna: All you got to have in the living room is a TV and some sofas, that's all you have. So you don't have to have a... 
Daniel: What? Like - so what?

Natalie: Yeah. You need sofas.

Daniel: Like four by four?

Natalie: You need enough - we - you - you need enough to fit at least a sofa and a TV.

Michael: Five by four.

Natalie: That's also gigantic.

Daniel: It depends what sofa you get.

Natalie: Yeah. Just get one of those tiny ones.

Daniel: Four by four or four by five?

\subsection{Showing agency through a repertoire of discourses}

The co-construction processes were more accessible for all students than the modification and interpretation processes. Adrian and Nicholas and Daniel and Michael often worked together by shifting through various modes of collaboration (co-construction, integration, modification). They flexibly utilised a repertoire of discourses (negotiary, interpretive, informative). The same can be said, to a lesser extent, of Natalie. Even Ji-na, who was largely not participating during the task, accessed many discourses (Tables 3 and 4). Aruna and Nafisa almost exclusively drew on negotiary discourses and thus took part in co-construction processes. A further look at the data revealed that they also rarely used literate mathematics discourse that, in our dataset, was required in the modification and interpretation processes.

As an example, the following excerpt (Excerpt 5) is a part of a larger modification process. In the excerpt, Michael uses "bossy" language (informative discourse): "We need 16". Yet overall, Michael showed secondary agency, as his initiative was taken further by other students, and the final argument was proposed by Daniel. During the modification process, Aruna and Natalie discussed the furniture of the room, while Michael led the conversation as the primary agent. This is a rare example of Aruna drawing on interpretive discourse ("All you're going to need...") that challenged Michael's initiative. But from the viewpoint of solving the task, Aruna's contribution is small, as pondering the furniture is finally ignored by Michael.

Excerpt 5: Group 1, $\mathrm{DT}_{\text {id }}=15$

Michael: We need 16. The total area is 60 square metres.

Natalie: We can make the bedroom a bit smaller because you don't need so big for a bedroom.

Michael: Four by 16.

Aruna: All you're going to have is a bed...

Natalie: A bed and a computer.

Aruna: ....and a wardrobe.

Natalie: And a desk. That's all you need.

Aruna: Yeah.

Natalie: The wardrobe's like stuck into the wall so...

Daniel: So what do you want the bedroom to be?

Natalie: Like - like...

Daniel: Because we have 20 more - 20 more. 


\subsection{A new discourse identified: Invalidation discourse}

We identified a new discourse: invalidation discourse. Invalidation discourse focused on framing a partner's contribution to the collaboration process as completely invalid, without further discussion. It was identified within all of the collaboration modes (co-construction, integration, modification). The invalidation discourse did not always manifest through words such as "no", but through ignoring and neglecting the contribution of another student. This discourse appears to differ from the interpretive discourse which aims to tease out the meaning behind one's argument. Often, it conveyed a sense of rejection. The totality of the invalidation discourse compared to the interpretive one can be seen in Excerpt 6:

Excerpt 6: Group 1, $\mathrm{DT}_{\mathrm{id}}=5$

Natalie: I'll make the toiler smaller, okay? It's just a draw...

Daniel: So toilet should be like one by one?

Aruna: Yes.

Natalie: No. That'll be tiny. You know what one by one is?

The invalidation discourse was not necessarily insensitive or unkind towards others. It was carried out by someone who thinks they know, towards others who they think do not know. In the example above, Natalie is probably correct; a toilet that is one square meter is tiny! Even then, it was evident in the data that invalidation discourse built on totality.

As noted, the task resulted in an intertwinement of mathematical (both literate and colloquial) and non-mathematical language. This was seen with invalidation discourse too, as the debunked arguments reflected all sorts of knowledge, not only mathematical. Not all general knowledge shared during the solving of the task was taken as valid knowledge by the students. As invalidation discourse was used towards another student, we coded that to represent "no agency", as the discourse completely deemed one's contribution as invalid. For example, Aruna's own experiences of apartments in Sri Lanka were actively deemed as invalid through the invalidation discourse. The other students saw Aruna's knowledge and experiences restricting the CPS process. Therefore, her agency was restricted multiple times, even though she actively tried to participate throughout the whole CPS process. Excerpt 7 shows how invalidation discourse manifested in practice:

Excerpt 7: Group 1, $\mathrm{DT}_{\text {id }}=21$

Daniel: Every apartment has a balcony.

Natalie: Not every...

Aruna: Daniel, not every. My dad has an apartment, right, in Sri Lanka and he doesn't have a balcony.

Natalie: That's in Sri Lanka. We're talking about Australia.

Aruna: Yeah. But there's a lot of apartments in Sri Lanka that have lots of balconies.

The invalidation discourse often aimed to advance the CPS process rather than disrupt it, as invalid contributions were the ones that were seen as disruptive. Restricting another student's agency led to the enhancement of the problem-solving process and, finally, to a more elaborated answer to the task at hand. For example, Nafisa often tried to take part in the co-construction processes but was neglected through invalidation by Nicholas and Adrian. Excerpt 8 shows 
how Nafisa tried to take part in a co-construction process that drew heavily on literate mathematics discourse. Her agency was restricted through direct invalidation ("No."):

Excerpt 8: Group 2, $\mathrm{DT}_{\text {id }}=6$

Nicholas: Okay. The kitchen will be a three by three, the bedroom will be a three by four.

Adrian: Is that what we have left?

Nicholas: Yes.

Adrian: We - it that's 30, that's 39, we can have 39 so we have 21 square metres left. Nicholas: Twenty-one, 21.

Adrian: So, so.

Nafisa: So we can make like the bedroom like 11 and then 10 for the kitchen.

Adrian: Ten for the kitchen.

Nicholas: No.

Adrian: No. Eight for the kitchen.

Nicholas: You can't - how are you going to make 10?

Nafisa: Oh yeah, yeah, yeah.

Nicholas: It has to be nine.

Nafisa: Oh yeah, yeah.

Adrian: Oh yeah.

Nicholas: Squares, come on!

\section{Discussion}

We have drawn on Mueller et al. (2012) to conceptualise agency as a socially constructed phenomenon that lies in the heart of mathematical collaboration. We applied this framework in the contexts of open-ended real-life tasks. Our analytical pathway offers future research a way to unpack how agency is shared in group collaboration. Our study confirms that through a careful research design and transparent reporting of the analytical process, the framework by Mueller et al. offers valuable information about the contributions of students in CPS drawing on real-life contexts. Overall, our study highlights the complex nature of student agency; we elaborate on what is meant by "supporting agency" in CPS.

As collaborative activities and "knowledge co-construction" are highly appreciated goals in education (Iiskala et al., 2011; Lee et al., 2006; Slavit \& Nelson, 2010; Stein et al., 2008), it is encouraging that in our study, co-construction processes through negotiary discourses characterised the CPS process of both of the student groups. Our findings show that integration and modification processes were most often utilised by those who were already leading the overall CPS process through primary agency. This is an interesting finding given that, as Mueller et al. (2012) put it, the way co-construction is often valued might undermine integration and modification processes that are just as important for CPS. The open-ended real-life task turned the tables and changed co-construction (and the negotiary discourses within) as the most accessible form of mathematical CPS. All the students, other than Ji-na who mostly did not participate in the task, were able to share their agency together.

The CPS task required both literate and colloquial mathematics discourses (Ben-Yehuda et al., 2005; Moschkovich, 2007) and knowledge beyond "mathematical". While our coding of 
the students' utterances in terms of literate and colloquial discourse was simplistic, it enabled us to dig deeper into how agency was shared by the students. Michael, Daniel, Adrian, and Nicholas, who the teacher characterised as high performing students, utilised literate mathematics discourses as a part of their discursive repertoires; Natalie to a lesser extent ("fairly low abilities"); and Aruna, Nafisa, and Ji-na rarely. It seems that the open-ended real-life task enabled students to share agency, but mostly in terms of colloquial and non-mathematical discourses. This finding reflects earlier research on mathematical authority, as historically, who has authority in mathematics classrooms has been restricted (Civil \& Hunter, 2015; Esmonde \& Langer-Osuna, 2013; Langer-Osuna, 2018). Indeed, in our dataset, the boys were the ones who mostly showed primary and drew on literate mathematics discourses, and Aruna's nonWestern experiences were debunked. These processes might reflect systemic injustice in mathematics education, but of course our study only included two student groups. Nevertheless, the viewpoints of gender and ethnicity offer important aspects for future research in the context of open-ended real-life tasks. In Langer-Osuna et al.'s (2020) study, students' intellectual authority was shown to be more stable during CPS than their social authority; a similar process was seen here with student agency. This raises questions about the purpose of the task. Promoting activities with shared agency in mathematics is a worthwhile goal itself. However, if tasks aim to foster literate mathematics discourses as a part of collaboration, it might be that more organised instructions or teacher scaffolding is needed.

Mueller et al. (2012) concluded that all three collaboration modes (co-construction, integration, modification) are equally important for CPS. We complexify this argument a bit. While our analysis supports Mueller et al.'s argument that different modes of collaboration include different forms of agency, we note that shifting between discourses (negotiary/ interpretive/informative, literate/colloquial) is a manifestation of agency too: A more varied repertoire of discourses reflected higher student agency. In our data, some students translated other students' colloquial mathematics discourse into literate discourse; certainly such processes reflect primary and secondary agency. Future studies could examine how the diversity of discourses, and thus agency, during CPS could be supported.

We identified a novel invalidation discourse. This discourse highlights the complex way mathematics learners use their agency in desirable and undesirable ways (Nieminen \& Tuohilampi, 2020). As earlier studies have noted, the contribution of marginalised students such as non-native language speakers might get neglected in mathematical CPS (Esmonde \& LangerOsuna, 2013; DeJarnette \& González, 2015). Aruna's knowledge and experiences of Sri Lanka were deemed invalid, which restricted Aruna's agency during collaboration. It has been stated that during CPS processes, students' literate mathematical contributions might be seen as invalid (Campbell et al., 2020; Nordin \& Björklund Boistrup, 2018); our findings confirm that openended real-life tasks also hold affordances for invalidating students' colloquial and nonmathematical contributions (Esmonde \& Langer-Osuna, 2013). While there is a considerable amount of literature on learners' everyday knowledge being rejected in mathematics classrooms (e.g. Gorgorió \& Planas, 2005), we have raised this issue specifically in relation to student agency during mathematical CPS. An obvious implication for practice is to avoid such circumstances, as invalidation might reflect the processes of racism, ableism, and so forth. In our dataset, invalidation discourse restricted Aruna from bringing in her own cultural knowledge (see also Civil \& Hunter, 2015). However, from the viewpoint of the task, invalidation discourse advanced CPS, not hindered it. Indeed, conflict itself needs not be avoided in mathematical CPS, especially in heterogeneous learner spaces (Esmonde \& Langer-Osuna, 2013). Aruna's experiences from Sri Lanka started a conversation that first formed a barrier to the CPS process but then led into 
argumentation and collaboration and, finally, a solution. It made sense that her contribution was invalidated if the ultimate goal for CPS was seen to be the final solution. On the other hand, if the ultimate educational goal was "collaboration", this situation could be deemed problematic. If open-ended real-life tasks aim to foster diverse experiences and ways of knowing, the educational goals need to be acknowledged in task design. In classroom situations, teachers may prepare students about how to deal with emerging conflict situations as part of the CPS instructions. Perhaps student participation in task design would hold affordances for producing motivating real-life tasks that aim for shared agency by allowing diverse personal experiences being considered in the process?

Our study has its limitations. First, our analysis did not consider the temporal shifts of agency. We acknowledge that the temporal aspect of agency could be a useful area to pursue in future research. In our analysis, and consistent with Mueller et al.'s (2012) approach, our analytical focus was on the overall argumentation of the students. When solving the task, the students in our study shifted between different modes of collaboration over time. Future studies could track the temporal changes or different trajectories of agency in the course of the CPS activity. Furthermore, the student activities were filmed in a laboratory classroom, allowing the students' conversations to be recorded in detail. Every effort was made to preserve existing social relationships between the students and their teacher for the filming, but we understand the limitations of the laboratory setting for interpreting classroom norms. Further studies could apply these ideas in various socio-cultural-political classroom contexts. Our lack of students' background information restricts us from broadening our implications; arguably, students' previous history in mathematics classrooms affects their agentic behaviour. Also, what exactly is the interplay of students' prevalent identity and positioning (macro-level) and their situational agency (micro-level) forms an interesting future trajectory on studies concerning, for example, agency and power. Future studies could focus on participatory research designs with the students. Here, it was the researchers who analysed students' agency; as Nieminen and colleagues (2021) note, studies on "agency" miss something crucial if the targets of the study cannot exercise their agency in the research process.

Our study has offered a micro-level investigation of shared (and non-shared) student agency in mathematical CPS. Finally, we note that we do not want to further construct the divisive values between mathematical and non-mathematical—or, indeed, the division itself. Instead, we suggest that we need to rethink these boundaries in task design and reach for their intersection where the lived and personal becomes mathematical. Our study is certainly not the first to have suggested something along these lines, but we have investigated the affordances that open-ended real-life CPS tasks hold for this. While carefully designed, open-ended CPS tasks might truly enable students from diverse backgrounds to show their agency through collaboration.

Funding Open access funding provided by University of Eastern Finland (UEF) including Kuopio University Hospital.

Open Access This article is licensed under a Creative Commons Attribution 4.0 International License, which permits use, sharing, adaptation, distribution and reproduction in any medium or format, as long as you give appropriate credit to the original author(s) and the source, provide a link to the Creative Commons licence, and indicate if changes were made. The images or other third party material in this article are included in the article's Creative Commons licence, unless indicated otherwise in a credit line to the material. If material is not included in the article's Creative Commons licence and your intended use is not permitted by statutory regulation or exceeds the permitted use, you will need to obtain permission directly from the copyright holder. To view a copy of this licence, visit http://creativecommons.org/licenses/by/4.0/. 


\section{References}

Alrø, H., \& Skovsmose, O. (2003). Dialogue and learning in mathematics education. Kluwer Academic Publishers.

Arnold, J., \& Clarke, D. J. (2014). What is 'agency'? Perspectives in science education research. International Journal of Science Education, 36(5), 735-754.

Ben-Yehuda, M., Lavy, I., Linchevski, L., \& Sfard, A. (2005). Doing wrong with words: What bars students' access to arithmetical discourses. Journal for Research in Mathematics Education, 36(3), 176-247.

Beswick, K. (2011). Putting context in context: An examination of the evidence for the benefits of 'contextualised' tasks. International Journal of Science and Mathematics Education, 9(2), 367-390.

Boaler, J., \& Greeno, J. G. (2000). Identity, agency, and knowing in mathematics worlds. Multiple Perspectives on Mathematics Teaching and Learning, 1, 171-200.

Campbell, T. G., Boyle, J. D., \& King, S. (2020). Proof and argumentation in K-12 mathematics: A review of conceptions, content, and support. International Journal of Mathematical Education in Science and Technology, 51(5), 754-774.

Chan, M. C. E., \& Clarke, D. (2017). Structured affordances in the use of open-ended tasks to facilitate collaborative problem solving. ZDM-Mathematics Education, 49(6), 951-963.

Chan, M. C. E., Clarke, D. J., \& Cao, Y. (2018). The social essentials of learning: An experimental investigation of collaborative problem solving and knowledge construction in mathematics classrooms in Australia and China. Mathematics Education Research Journal, 30(1), 39-50.

Chizhik, A. W. (2001). Equity and status in group collaboration: Learning through explanations depends on task characteristics. Social Psychology of Education, 5(2), 179-200.

Civil, M., \& Hunter, R. (2015). Participation of non-dominant students in argumentation in the mathematics classroom. Intercultural Education, 26(4), 296-312.

Clarke, D. J. (2001). Untangling uncertainty, negotiation and inter-subjectivity. In D. Clarke (Ed.), Perspectives on practice and meaning in mathematics and science classrooms (pp. 33-52). Kluwer Academic Publishers.

Clarke, D. J., \& Sullivan, P. (1990). Is a question the best answer? Australian Mathematics Teacher, 46(3), 3033.

Clarke, D. J., Mesiti, C., Jablonka, E., \& Shimizu, Y. (2006). Addressing the challenge of legitimate international comparisons: Lesson structure in the USA, Germany and Japan. In D. J. Clarke, J. Emanuelsson, E. Jablonka, \& I. A. C. Mok (Eds.), Making connections: Comparing mathematics classrooms around the world (pp. 23-45). Sense Publishers.

CREA [Centre of Research in Theories and Practices that Overcome Inequalities]. (2012). INCLUD-ED Strategies for inclusion and social cohesion in Europe from education: Final report. CREA, University of Barcelona.

Davis, B., \& Simmt, E. (2003). Understanding learning systems: Mathematics education and complexity science. Journal for Research in Mathematics Education, 34(2), 137-167.

DeJarnette, A. F., \& González, G. (2015). Positioning during group work on a novel task in Algebra II. Journal for Research in Mathematics Education, 46(4), 378-422.

Emirbayer, M., \& Mische, A. (1998). What is agency? American Journal of Sociology, 103(4), 962-1023.

Esmonde, I., \& Langer-Osuna, J. M. (2013). Power in numbers: Student participation in mathematical discussions in heterogeneous spaces. Journal for Research in Mathematics Education, 44(1), 288-315.

Forman, E. A., Larreamendy-Joerns, J., Stein, M. K., \& Brown, C. A. (1998). "You're going to want to find out which and prove it": Collective argumentation in a mathematics classroom. Learning and Instruction, $8(6)$, 527-548.

Gorgorió, N., \& Planas, N. (2005). Social representations as mediators of mathematics learning in multiethnic classrooms. European Journal of Psychology of Education, 20(1), 91-104.

Gresalfi, M., Martin, T., Hand, V., \& Greeno, J. (2009). Constructing competence: An analysis of student participation in the activity systems of mathematics classrooms. Educational Studies in Mathematics, 70(1), 49-70.

Iiskala, T., Vauras, M., Lehtinen, E., \& Salonen, P. (2011). Socially shared metacognition of dyads of pupils in collaborative mathematical problem-solving processes. Learning and Instruction, 21(3), 379-393.

Jurdak, M. E. (2006). Contrasting perspectives and performance of high school students on problem solving in real world, situated, and school contexts. Educational Studies in Mathematics, 63(3), 283-301.

Langer-Osuna, J. M. (2018). Exploring the central role of student authority relations in collaborative mathematics. ZDM-Mathematics Education, 50(6), 1077-1087.

Langer-Osuna, J., Munson, J., Gargroetzi, E., Williams, I., \& Chavez, R. (2020). "So what are we working on?": How student authority relations shift during collaborative mathematics activity. Educational Studies in Mathematics, 104(3), 333-349. 
Lee, E. Y., Chan, C. K., \& van Aalst, J. (2006). Students assessing their own collaborative knowledge building. International Journal of Computer-Supported Collaborative Learning, 1(1), 57-87.

Lerman, S. (2000). The social turn in mathematics education research. In J. Boaler (Ed.), Multiple perspectives on mathematics teaching and learning (pp. 19-44). Ablex.

Matusov, E., von Duyke, K., \& Kayumova, S. (2016). Mapping concepts of agency in educational contexts. Integrative Psychological and Behavioral Science, 50(3), 420-446.

Moschkovich, J. (2007). Examining mathematical discourse practices. For the Learning of Mathematics, 27(1), 24-30.

Mueller, M., Yankelewitz, D., \& Maher, C. (2012). A framework for analyzing the collaborative construction of arguments and its interplay with agency. Educational Studies in Mathematics, 80(3), 369-387.

Nieminen, J. H., Tai, J., Boud, D., \& Henderson, M. (2021). Student agency in feedback: beyond the individual. Assessment \& Evaluation in Higher Education, 1-14. https://doi.org/10.1080/02602938.2021.1887080.

Nieminen, J. H., \& Tuohilampi, L. (2020). 'Finally studying for myself'-Examining student agency in summative and formative self-assessment models. Assessment \& Evaluation in Higher Education, 45(7), 1031-1045.

Nordin, A. K., \& Björklund Boistrup, L. (2018). A framework for identifying mathematical arguments as supported claims created in day-to-day classroom interactions. The Journal of Mathematical Behavior, 51, 15-27.

OECD. (2013). PISA 2015 draft collaborative problem solving framework. OECD.

Powell, A. B. (2006). Socially emergent cognition: Particular outcome of student-to-student discursive interaction during mathematical problem solving. Horizontes, 24(1), 33-42.

Saldaña, J. (2016). The coding manual for qualitative researchers. Sage.

Slavit, D., \& Nelson, T. H. (2010). Collaborative teacher inquiry as a tool for building theory on the development and use of rich mathematical tasks. Journal of Mathematics Teacher Education, 13(3), 201-221.

Stein, M. K., Engle, R. A., Smith, M. S., \& Hughes, E. K. (2008). Orchestrating productive mathematical discussions: Five practices for helping teachers move beyond show and tell. Mathematical Thinking and Learning, 10(4), 313-340.

Sullivan, P., Knott, L., \& Yang, Y. (2015). The relationships between task design, anticipated pedagogies, and student learning. In A. Watson \& M. Ohtani (Eds.), Task design in mathematics education: An ICMI study 22 (pp. 83-114). Springer International Publishing.

Wagner, D. (2004). Critical awareness of voice in mathematics classroom discourse: Learning the steps in the "dance of agency". Proceedings of the 28th Conference of the International Group for the Psychology of Mathematics Education, Vol. IV (pp. 401-408). Bergen.

Wagner, D. (2007). Students' critical awareness of voice and agency in mathematics classroom discourse. Mathematical Thinking and Learning, 9(1), 31-50.

Yeo, J. B. (2017). Development of a framework to characterise the openness of mathematical tasks. International Journal of Science and Mathematics Education, 15(1), 175-191.

Publisher's note Springer Nature remains neutral with regard to jurisdictional claims in published maps and institutional affiliations.

\section{Affiliations}

\section{Juuso Henrik Nieminen ${ }^{1}$ - Man Ching Esther Chan ${ }^{2}$ - David Clarke ${ }^{2}$}

1 School of Educational Sciences and Psychology, University of Eastern Finland, Joensuu, Finland

2 Melbourne Graduate School of Education, University of Melbourne, Melbourne, Australia 